\title{
O SIGNIFICADO DO TRABALHO PARA JOVENS APRENDIZES
}

\section{THE MEANING OF THE WORK FOR YOUNG APPRENTICES}

\author{
ROSANI ELISABETE GRAEBIN \\ Mestranda no Programa de Pós-Graduação em Administração \\ Universidade de Caxias do Sul - UCS \\ E-mail: rosanigraebin@hotmail.com / Orcid: http://orcid.org/0000-0002-6489-9225 \\ Endereço: Rua Reinaldo Scherner, 53/701 - Caxias do Sul/RS \\ JULIANA MATTE \\ Doutoranda no Programa de Pós-Graduação em Administração \\ Universidade de Caxias do Sul - UCS \\ E-mail: ju.cxs1@gmail.com / Orcid: http://orcid.org/0000-0003-0945-2479
}

\begin{abstract}
FABIANO LARENTIS
Doutor em Administração

Professor no Programa de Pós-Graduação em Administração - Universidade de Caxias do Sul (UCS)

E-mail: flarenti@ucs.br / Orcid: http://orcid.org/0000-0001-8390-0271
\end{abstract}

\section{MARTA ELISETE VENTURA DA MOTTA}

Doutora em Administração

Professora no Programa de Pós-Graduação em Administração na Universidade de Caxias do Sul - UCS

E-mail: martamotta1234@gmail.com / Orcid: http://orcid.org/0000-0001-5551-2343

\section{PELAYO MUNHOZ OLEA \\ Doutor em Administração}

Professor no Programa de Pós-Graduação em Administração na Universidade de Caxias do Sul - UCS E-mail: pelayo.olea@gmail.com / Orcid: http://orcid.org/0000-0003-2183-8112

\section{RESUMO}

As constantes transformações no mundo do trabalho, tanto materiais quanto subjetivas, promovem necessidades de buscar novas compreensões a respeito do trabalho, seu sentido e significado. As relações entre jovens e trabalho, suas condições de vida e as oportunidades de desenvolvimento que lhes são oferecidas se apresentam como fatores que contribuem para a busca dessa compreensão. $O$ objetivo do presente estudo é compreender o significado do trabalho para jovens que estão ingressando no mercado de trabalho por meio do contrato profissional de aprendizagem no Centro de Integração Empresa Escola - CIEE, unidade operacional de Caxias do Sul - RS. A pesquisa é caracterizada por uma abordagem qualitativa, através de entrevistas individuais com 50 jovens que participam do programa Jovem Aprendiz. Os resultados demonstram que a construção do significado do trabalho envolve experiência, conhecimento, dinheiro e realização. Fatores de criatividade, como autonomia, liberdade de trabalho, flexibilidade e reconhecimento não se mostraram relevantes, indicando que, mais importante do que o ambiente de trabalho em si, é o que ele proporciona como fator social. Palavras-chave: Significado do trabalho. CIEE. Aprendiz.

Data de submissão: 27/11/2017. Data de aceite: 25/03/2019. Data de publicação: 13/04/2019. 


\begin{abstract}
The constant transformations in the world of work, both material and subjective, promote the need to seek new understandings about work, its meaning and meaning. The relationships between youth and work, their living conditions and the opportunities for development offered to them are factors that contribute to the search for this understanding. The objective of the present study is to understand the meaning of work for young people entering the labor market through the professional contract of learning in the Center of Integration Company School - CIEE, operational unit of Caxias do Sul - RS. The research is characterized by a qualitative approach, through individual interviews with 50 young people who participate in the Young Apprentice program. The results demonstrate that building the meaning of work involves experience, knowledge, money, and achievement. Creativity factors such as autonomy, freedom of work, flexibility and recognition were not relevant, indicating that, more important than the work environment itself is what it provides as a social factor.
\end{abstract}

Keywords: Meaning of work. CIEE. Apprentice.

\title{
1 INTRODUÇÃO
}

O mundo do trabalho tem apresentando grandes transformações nos últimos tempos, diante disso, percebe-se uma imprecisão e complexidade evidenciadas pelas diferentes concepções acerca do significado do trabalho. Essa visão é verificada a partir dos estudos de Tolfo et al. (2005), Oliveira et al. (2004), Tolfo e Piccinini (2007), Alberton (2008), Dejours (2015), demonstrando as transformações de seu significado, ao longo da história.

O trabalho tem sido considerado não somente um meio de obter renda, mas, também, como uma atividade que assegura realização pessoal, status e oportunidade de estabelecer e manter contatos interpessoais (KUBO; GOUVÊA, 2012). Os autores apontam que a relevância do trabalho pode ser analisada pela quantidade de horas por dia que as pessoas permanecem trabalhando e que também são significativos os dias, os meses e os anos investidos na preparação para essa atividade, ou seja, na formação escolar que oferece a capacitação básica para o exercício das atividades na profissão escolhida.

Dutra-Thomé e Koller (2014), a partir de estudo composto por uma amostra 7.425 jovens entre 14 e 24 anos, apontaram a preponderância de uma visão moralista e mercadológica de trabalho, com um olhar na atividade laboral enquanto fonte de desenvolvimento e crescimento pessoal. As autoras concluíram que essa perspectiva pode minimizar os efeitos negativos do trabalho sobre o indivíduo e enfraquecer o conceito do trabalho infanto-juvenil protegido.

Complementando, os jovens estão mais sensíveis a transformações do mercado de trabalho, encontrando dificuldades em acessar e manter o primeiro emprego (PAULINO, 2016). O mercado trabalho necessita maiores investimentos em educação e em treinamento profissional na busca por profissionais qualificados, assim, ao mesmo tempo que se observa jovens ansiosos por atuar em algo que lhes satisfaça de forma pessoal (DUTRA-THOMÉ; QUEIROZ TELMO; KOLLER, 2010, ARNETT, 2010). Em contrapartida, ainda é representativo o modelo predominante no mundo do trabalho que se baseia nas concepções enquanto fonte de renda e sobrevivência, minimizando, assim, o foco na realização pessoal (ZANINI et al., 2004).

Segundo o Instituto Brasileiro de Geografia e Estatística - IBGE (2015), os jovens representam um quarto da população do país. Isso significa 51,3 milhões de jovens, entre 15 
e 29 anos, vivem no Brasil. Pesquisa realizada pela Agenda Juventude Brasil apontou ser a inserção no mercado de trabalho um dos temas mais relevantes para a vida dos jovens no Brasil (SNJ, 2014).

Segundo o Ministério do Trabalho e Emprego - MTE (2014), entre os jovens, o desemprego e a rotatividade no trabalho são maiores. Não porque eles não sabem o que querem ou porque o mercado não os quer, mas porque o ingresso no mercado, muitas vezes, ocorre de forma precária, sem a qualificação necessária e jornadas de trabalho que desestimulam a continuidade dos estudos.

Entender o que esses jovens pensam acerca do significado do trabalho no início de suas vidas profissionais se faz necessário, pois afinam as expectativas e objetivos pessoais com os ideais profissionais. Portanto, o objetivo da pesquisa é compreender o significado do trabalho para jovens que estão ingressando no mercado de trabalho por meio do contrato profissional de aprendizagem no Centro de Integração Empresa Escola - CIEE, unidade operacional de Caxias do Sul - RS.

Para tal pesquisa, foram realizadas entrevistas com 50 jovens que estão estudando e trabalhando por meio do contrato de aprendizagem firmados pelo CIEE de Caxias do Sul - RS. As entrevistas foram feitas individualmente, utilizando questionário semiestruturado, com caráter exploratório. Os dados foram transcritos e submetidos a análise de conteúdo com o auxílio do software Nvivo $11^{\circledR}$. Os resultados estão expostos no decorrer desde artigo que se inicia com o referencial teórico sobre o significado do trabalho, estágio, aprendiz e CIEE-RS; permeia com a metodologia de pesquisa e finaliza com as entrevistas realizadas e as discussões dos resultados encontrados, bem como a conclusão.

\section{REFERENCIAL TEÓRICO}

\subsection{SIGNIFICADO DO TRABALHO}

Previamente à definição do significado do trabalho, é importante definir o termo "sentido" por meio de sua etimologia. A palavra sentido vem do latim sensus, compreendido como "faculdade da percepção, significado ou interpretação, percepção, sentimento, empreendimento", ou do verbo sentire: "perceber, sentir, saber" (HARPER, 2001). O significado, por sua vez, transcende, permanece além da relação Sujeito $\leftrightarrow$ Objeto (CODO, 1997). Aguiar (2006) e Tolfo et al. (2005), de certo modo, sintetizam estes conceitos e facilitam a compreensão ao sugerirem que os significados são coletivos, sociais, "dicionarizados", mais estáveis que os sentidos. Os sentidos, ao contrário, são compreendidos por estes autores como menos estáveis e mais subjetivos, pessoais.

Marx (1971) mostra a importância do trabalho na vida do indivíduo ao colocar que o homem só está vivo à medida em que é produtivo, onde sua autorrealização só pode ser compreendida por meio da sua ligação com a concepção do trabalho. Lhuilier (2013) aponta que a atividade de trabalho tem um caráter fundamentalmente social. $\mathrm{O}$ trabalho é realizado com os outros, para os outros, e ele é subordinado a um objetivo coletivo.

Portanto, por ser fruto de uma realidade social e de uma realidade "subjetivada", o trabalho é um fenômeno psicossocial - construído por processos perceptivos e subjetivos das pessoas (PEIRO et al., 1996). Corroborando com os autores, Jacques (1996) aponta que o papel do trabalhador é um dos papéis sociais mais representativos do eu: os atributos do trabalho, a associação do espaço e/ou da categoria de trabalho ao prestígio ou desprestígio social, tudo 
reverbera na qualificação de si mesmo.

Para Osipow e Fitzgerald (1986), ter um trabalho valorizado pela sociedade - e ter sucesso nele - aumenta a autoestima e facilita o desenvolvimento de um senso de identidade cada vez mais seguro e estável. Alberton e Piccinini (2009) realizaram uma pesquisa e os resultados mostraram que um trabalho que tem sentido permite o uso das capacidades individuais e recompensa adequadamente o trabalhador.

Além disto, o sentido do trabalho deve estar relacionado ao prazer em trabalhar, ao uso da criatividade, ao aprendizado e ao reconhecimento das competências do trabalhador. Ono (2010) estudaram os sentidos do trabalho para um grupo de profissionais de $\mathrm{Tl}$ e descobriram que o trabalho com sentido é aquele que permite aprendizado, identificação com a tarefa, remuneração adequada, atividades não rotineiras, que tragam desafios e contribuam para com a sociedade.

Vale destacar que o conceito de trabalho levanta questões não só vinculadas à busca de melhores condições de vida, mas também, às barreiras que o indivíduo cria em torno de trabalho e lazer, trabalho e família, tempo e espaço, mercado de trabalho e empregabilidade (GAMST, 1995). Se, de um lado, fornece o essencial para a sobrevivência e se apresenta como fonte de identidade e possibilidade de realização, de outro, ao se apresentar como fonte de experiências humanas, proporciona alegria, exuberância e satisfação, mas também desapontamento, tristeza, angústia e desespero (MORIN, 2001; ARDICHVILI; KUCHINKE, 2009).

Dessa forma, o significado de trabalho retrata uma construção formada pelo coletivo dentro de um contexto histórico, social e econômico. Já o sentido, é consequência de uma experiência individual e subjetiva, tendo, como base, os significados coletivos. Constantes transformações dos sentidos e significados do trabalho estão ocorrendo, uma vez que se estabelecem a partir de uma relação ativa com a realidade (DUTRA-THOMÉ; KOLLER, 2014).

Nesse contexto, tem-se admitido a distinção entre os sentidos e os significados do trabalho, concordando que, na verdade, são elementos dialéticos. Os significados são a acumulação de compreensões de grupos à respeito de algum fenômeno. Já os sentidos, dizem respeito às transformações diante das experiências acumuladas resultante das atividades das pessoas, que, assim, colaboram para a mudança dos significados, que antes serviriam de base para os sentidos (LIMA, 2016).

De acordo com Tolfo et al. (2005), os estudos sobre os sentidos do trabalho, onde significado surge como uma das características que the confere sentido, intensificou-se na década de 1970 e, desde então, é dividido em: sócio histórica, construcionista, cognitivista e humanista. Apesar de difundida e consolidada, surge outra corrente epistemológica: psicodinâmica do trabalho, cujo precursor foi Jacques Christophe Dejours (SCHWEITZER et al., 2016). A seguir, as cinco perspectivas e suas características:

\subsubsection{Perspectiva sócio histórica}

Segundo Tolfo et al. (2005), a significação na perspectiva sócio histórica é vista como a generalização das práticas sociais, ou seja, o significado é entendido como coletivo e se dá por meio das interações sociais. Com esse mesmo olhar, Medeiros (2006) acredita que o homem, para sua produção e sobrevivência ao longo da sua vida, acumula e fixa formas de agir, pensar, falar, escrever e sentir que se transformam com o desenvolvimento das relações sociais estabelecidas entre os homens.

Conforme os autores Aguiar et al. (2009), o homem, ao mesmo tempo em que atua no 
mundo, modifica a realidade e a si mesmo. Sendo assim, os significados sociais, generalizados e mediadores do processo de comunicação, são produções históricas e sociais relativamente estáveis e compartilhadas. Portanto, os significados sociais, que serão internalizados e transformados em sentidos, só existem porque os homens os constituíram e os constituem permanentemente (SCHWEITZER et al., 2016).

\subsubsection{Perspectiva construcionista}

A abordagem construcionista, segundo Tolfo et al. (2005), é construída com base no entendimento comum que as pessoas constroem e, com base nesses conhecimentos, elas constituem seus significados. Isso ocorre porque o sentido se constitui nas consciências dos indivíduos que se tornaram pessoas por meio dos processos sociais.

Para os autores Spink (2010) e Lima (2013), a produção de sentidos se dá num contexto em interação e com interferências por questões de ordem histórica e cultural, permitindo com que a pessoa se relacione com situações e fenômenos sociais. Dessa forma, as pessoas constroem o mundo ao construir sentidos, por meio de repertórios individuais e sua identidade para esses sentidos. A realidade é construída a partir do entendimento de senso comum, cuja compreensão se constitui em sentidos (SPINK, 2010).

\subsubsection{Perspectiva cognitivista}

O grupo de investigação Meaning of Work International Research Team (MOW) definiu, na década de 1980, o significado do trabalho como sendo multidimensional e dinâmico, formado pela interação entre variáveis pessoais e ambientais e influenciado pelas mudanças no ser humano ao seu redor ou no próprio trabalho (RUIZ-QUINTANILLA; CLAES, 2000; TOLFO, 2015). Segundo esse grupo, o significado do trabalho é uma cognição social que envolve aspectos históricos, econômicos, políticos e culturais (BENDASSOLLI; GONDIM, 2014). O MOW analisou em três dimensões o trabalho, conforme Ruiz-Quintanilla e Claes (2000):

a) centralidade do trabalho: relacionada à identificação pessoal com o trabalho, ao seu valor e importância em relação às outras esferas da vida;

b) normas sociais sobre o trabalho: crenças e expectativas sobre direitos e deveres no trabalho; e

c) resultados valorizados do trabalho/metas do trabalho: razões para trabalhar e o que se objetiva ao trabalhar.

A primeira dimensão é centralidade do trabalho. A equipe do MOW define centralidade como a importância do trabalho na vida do indivíduo em um dado momento de sua história pessoal. Os resultados obtidos indicaram que o trabalho se encontra em segundo lugar em termos de importância. O primeiro é a família e o terceiro é o lazer.

A segunda dimensão do modelo são as normas sociais do trabalho. No modelo do MOW, são compostas por dois tipos de orientações: i) orientação normativa do trabalho como obrigação; ii) orientação normativa do trabalho como direito. Dizem respeito ao que as pessoas esperam do trabalho e também ao que supõem ser o correto oferecerem e receberem ao trabalhar. Como destacam Quintanilla e Wilpert (1991), ambas orientações são derivadas do conceito de contrato psicológico, o qual pode ser definido como uma forma de entendimento subjetivo do indivíduo acerca das promessas de trocas recíprocas entre ele e a organização, ou entre ele e a sociedade (ROUSSEAU, 1995).

A terceira dimensão são os valores do trabalho ou os resultados valorizados do trabalho e a importância das metas laborais. Os resultados valorizados do trabalho são 
elementos cognitivos que agem como guias, como ideais, sobre a postura do indivíduo no trabalho - o que ele gostaria de realizar por meio do trabalho e o que ele espera deste. Já a importância das metas de trabalho é uma forma de atualização dos valores (MOW, 1987).

Nesse sentido, Lima (2016) enfatiza que a abordagem adotada por MOW considera, como necessidade indispensável do ser humano, conferir sentido às suas ações; nesse caso, a ação de trabalhar. O significado do trabalho é um dos três elementos específicos que dão sentido ao trabalho, pois nele está contido a apreensão e valorização da experiência de trabalho. Os outros dois elementos são a orientação, que está relacionada a inclinação para o trabalho, e a coerência, que diz respeito à integração das informações pessoais e dimensões sociais.

Para Borges e Barros (2015), o compartilhamento social construído no processo de socialização pode igualar ou diferenciar os indivíduos, que também sofrem influência de agentes, como a família, os grupos de amigos, os ambientes de trabalho, as instituições formadoras entre outros. Para os autores, essas vivências afetam diretamente a construção do significado do trabalho de forma individual.

A partir desses estudos, a autora Lívia Borges $(1997,1998)$ procurou adequá-los à realidade brasileira e aprofundou a análise sobre a estrutura fatorial das crenças sobre o trabalho a partir da diferenciação entre atributos valorativos (como o trabalho deve ser, às exigências sociais, à justiça no trabalho, ao esforço corporal e à desumanização, à realização pessoal e à sobrevivência pessoal e familiar) e descritivos (como o trabalho realmente é, o êxito e a realização pessoal, a justiça no trabalho, a sobrevivência pessoal e familiar, a independência econômica e a carga mental). Assim, elaborou o IST (Inventário do Significado do Trabalho), refletindo sobre esse significado à nível nacional.

Com relação à perspectiva social, Bauman (2000) entende que o contexto atual do trabalho está inserido em uma realidade participante da líquida sociedade moderna. Segundo o autor, esta sociedade possui as características dos líquidos, ou seja, ela decreta o fim das estruturas rígidas e racionais, dando lugar a uma sociedade voltada ao consumo, à flexibilidade, ao individualismo, à mobilidade e a liquidez das relações, consequência da aceleração do ritmo de vida. Dessa forma, o trabalho foi arrancado de suas raízes metafísicas, perdendo a sua centralidade e valores dominantes, presentes na modernidade sólida e no capitalismo pesado (BAUMAN, 2000).

\subsubsection{Perspectiva existencialista ou humanista-fenomenológica}

Morin (2001) descreve as cinco principais razões que levam as pessoas a trabalharem: realizar-se e atualizar suas competências e potencialidades; adquirir segurança e ser autônomo; relacionar-se com os outros e estar vinculado a grupos; prestar serviço à sociedade; e dar sentido à vida, incluindo fazer e se manter ocupado.

Segundo Morin (2001), é uma necessidade vital do ser humano dar sentido aos próprios atos, buscando dar às suas condutas um sentido aceitável para si e para a sociedade em que vive. O sentido do trabalho representa, então, um produto da atividade humana e pode ser descrito com base em três componentes: a significação do trabalho (representações que o sujeito tem de sua atividade e o valor que lhe atribui), a orientação do sujeito ao trabalho (inclinação para o trabalho, o que busca e o que guia suas ações) e a coerência que o trabalho tem para o sujeito, ou seja, o equilíbrio que ele espera de sua relação com o trabalho (MORIN, 2001). 


\subsubsection{Perspectiva da psicodinâmica do trabalho}

O autor Dejours (2015) iniciou os estudos com a psicodinâmica do trabalho, evidenciando que o trabalho precisa fazer sentido para o homem, seus pares a sociedade, sendo formado por dois componentes: o conteúdo significativo em relação ao sujeito e em relação ao objeto. O conteúdo significativo em relação ao sujeito é construído a partir da identidade pessoal e social do trabalhador, por meio de tarefas que executa, permitindo com que ele se identifique com aquilo que realiza (DEJOURS, 2015). Já o sentido do trabalho, nesse contexto, pode ser descrito como "uma representação individual e/ou coletiva do ato de trabalhar desenvolvida por meio de um processo de percepção e reprodução do sentido, onde se apreciam as situações vivenciadas no ambiente de trabalho e a representatividade destas para o trabalhador" (COSTA, 2013, p. 375).

Dejours (2011) identifica três elementos para explicação da construção de sentidos do trabalho, que são: as características das tarefas realizadas; a organização do trabalho; e as diferenças individuais. O sentido dependerá do modo como os trabalhadores subjetivam a vivência laboral nas novas formas de organização do trabalho, vivenciadas por eles nos diversos setores produtivos da sociedade (DEJOURS, 2011).

\subsection{APRENDIZ}

A aprendizagem é um instituto que cria oportunidades tanto para o aprendiz quanto para a empresa que o contrata, "pois dá preparação ao iniciante de desempenhar atividades profissionais e de ter capacidade de discernimento para lidar com diferentes situações no mundo do trabalho" (MTE, 2014). Segundo o artigo 62 da Lei 8.069 de 1990, "a aprendizagem é destinada à formação técnico-profissional metódica de adolescentes e jovens, desenvolvida por meio de atividades teóricas e práticas e que são organizadas em tarefas de complexidade progressiva" (MTE, 2014).

Em uma análise histórica, constatou-se que, a partir do Decreto-Lei № 4.481, de 16 de julho de 1942, a aprendizagem esteve vinculada ao Sistema " $\mathrm{S}$ ", atualmente composto por SENAI, SENAC, SENAR, SENAT e SESCOOP, respectivamente, Serviço Nacional de Aprendizagem na Indústria, Serviço Nacional de Aprendizagem no Comércio, Serviço Nacional de Aprendizagem no Serviço Rural, Serviço Nacional de Aprendizagem nos Transportes e Serviço Nacional do Cooperativismo.

Caso o sistema ' $\mathrm{S}$ " não venha a oferecer cursos ou vagas suficientes para atender à demanda das empresas, estas poderão ser suprida por entidades qualificadas em formação técnico-profissional metódica. Dentre elas, aquelas sem fins lucrativos que tenham por objetivo a assistência ao adolescente e a educação profissional, com registro no Conselho Municipal dos Direitos da Criança e do Adolescente (CMDCA), cabendo à inspeção do trabalho verificar a insuficiência de cursos ou vagas (art. 13, parágrafo único, do Decreto no 5.598/05).

Em 2003, o governo instituiu o primeiro programa específico para o jovem com foco na qualificação e na inserção ao mercado de trabalho, o PNPE - Programa Nacional de Estímulo ao Primeiro Emprego. Em seguida, consolidou outros programas, tais como o ProJovem (Programa Nacional de Inclusão de Jovens), em 2005, e o Aprendiz Legal, que teve lei aprovada em 2000, mas regulamentada em 2005 (MATSUZAKI, 2013).

Em 2005, regulamentada pelo Decreto no 5.598/2005, a Lei da aprendizagem instituiu que empresas de médio e grande porte são obrigadas a contratar jovens na condição de aprendiz, assegurando a formação técnico-profissional e realização de atividades compatíveis com a vida escolar e com o desenvolvimento físico, psicológico e moral do aprendiz. 
Para o MTE (2014), a formação técnico-profissional se realiza por meio de instituições legalmente qualificadas e o jovem precisa ter idade de 14 a 24 anos e estar matriculado em um curso de aprendizagem profissional.

O programa de aprendizagem técnico-profissional prevê a execução de atividades teóricas (sob orientação pedagógica da entidade qualificada em formação técnicoprofissional) e práticas (coordenadas pelo empregador), ambas supervisionadas pela entidade qualificadora (MTE, 2014). O contrato de aprendizagem pressupõe frequência escolar, horário especial para o exercício das atividades, programa de formação técnico-profissional e capacitação adequada ao mercado de trabalho, conforme a Lei da Aprendizagem.

Limitando o contrato de aprendiz por meio do Decreto, o governo visou propiciar reais condições de aprendizagem e minimizar os impactos do trabalho precoce (AMAZARRAY et al., 2009). Os autores ressaltam que o trabalho pode ter implicações positivas quando propicia aprendizagem e é revestido de significado, mas pode trazer impactos para seu desenvolvimento quando as condições laborais se apresentam desfavoráveis.

Assim, jovens aprendizes percebem o trabalho como a porta de entrada para o mundo adulto, como uma oportunidade de desenvolvimento e aprendizagem, além da conquista da independência financeira, o que favorece seu amadurecimento pessoal. $O$ trabalho também é percebido como fator de desenvolvimento de habilidades e competências capazes de favorecer a conquista de conhecimentos técnicos e a melhor compreensão acerca do mundo profissional (ALONSO et al., 2018).

\section{METODOLOGIA}

Esta pesquisa possui uma abordagem qualitativa, de caráter exploratório, e trabalhou com os processos de significação produzidos por seres humanos em suas realidades sociais (MINAYO, 2007).

A caracterização do objeto de estudo está no subcapítulo 3.1, a coleta de dados e o instrumento utilizado no subcapítulo 3.2 e a análise de dados e apresentação das categorias no subcapítulo 3.3 .

\subsection{CARACTERIZAÇÃO DO OBJETO DE ESTUDO}

O CIEE é uma associação filantrópica de direito privado, sem fins lucrativos, que propicia aos jovens estudantes brasileiros uma formação integral, ingressando-os ao mercado de trabalho, por meio de treinamentos, programas de estágio e aprendizado (CIEE, 2017). Foi criado em São Paulo há mais de 50 anos, com o objetivo específico de obter, junto às empresas, oportunidades de estágios para estudantes de cursos superiores. Este objetivo inicial foi modificado ao longo dos anos, quando passou a encaminhar para estágios também estudantes de cursos de ensino médio, além de prestar outros serviços gratuitos para a melhoria da formação profissionalizante dos candidatos (AVANZI, 2008).

O CIEE tem funções como: firmar convênios com as Instituições de Ensino, cadastrar estudantes em seu banco de dados, buscar oportunidades de estágio junto à empresas, formalizar convênios com as empresas, oferecer diversos tipos de cursos de capacitação presencial e à distância, encaminhar estudantes para os processos seletivos nas empresas, providenciar a contratação de estudantes aprovados e acompanhar os estágios por meio de relatórios de avaliação e visitas técnicas nas empresas para subsidiar as Instituições de Ensino (ROCHA, 2008).

Na unidade operacional de Caxias do Sul, objeto desse estudo, é desenvolvido apenas 
o Programa de Integração ao Mundo do Trabalho, com o estágio e a aprendizagem. O programa Aprendiz Legal conta com os serviços de assistente social, pedagoga, psicóloga e professores.

\subsection{COLETA DE DADOS}

Para a coleta de dados, foi utilizado o Questionário sobre Significados do Trabalho QST, de Goulart (2009), semiestruturado de questões abertas, aplicados a 50 (cinquenta) aprendizes ligados ao Programa Aprendiz Legal do CIEE - Caxias do Sul. A aplicação aconteceu em duas etapas: a primeira com a presença do pesquisador em uma sala com 14 aprendizes, sendo 12 da CEF e 02 do Banco do Brasil; a segunda etapa com a presença da especialista em pedagogia empresarial, contemplando 36 aprendizes de diversas turmas de aprendizado, convidados a participar de forma voluntária. As repostas dos questionários foram por escrito e o tempo de duração variou em média de 10 a 15 minutos para finalizar.

Após o término das entrevistas, os questionários foram analisados e numerados. Como não houve respostas em branco e as respostas estavam compreensíveis, nenhum instrumento foi descartado, mantendo o número inicial de 50 instrumentos válidos para análise de conteúdo.

\subsection{ANÁLISE DA PESQUISA}

Para a análise dos dados, optou-se por utilizar a análise de conteúdo (BARDIN, 2004). Primeiramente, após a transcrição das entrevistas, foi realizada uma primeira leitura do material transcrito, ou seja, uma leitura flutuante para a identificação dos temas e pontos recorrentes dos discursos, no grupo todo e em cada um individualmente. Posteriormente, foi realizada uma segunda leitura que originou uma síntese de cada pergunta do questionário.

A partir desta etapa, foi possível, identificar por meio da proximidade de significados, quatro categorias derivadas do tema trabalho. Em um segundo momento, foi realizada a análise de conteúdo no software Nvivo $11^{\circledast}$. O critério para a criação de categorias foi a posteriori, pois emergiram a partir das entrevistas (BARDIN, 2004). No Quadro 1, estão expostas as categorias e seus respectivos subtemas que serão posteriormente compartilhados na análise de conteúdo.

Quadro 1 - Categorias e subcategorias a posteriori

\begin{tabular}{|l|l|}
\hline \multirow{4}{*}{ Significado do Trabalho } & Conhecimento/Experiência \\
& Responsabilidade/Amadurecimento \\
& Dinheiro/Necessidade \\
& Realização \\
Independência & Futuro \\
\hline Trabalho Atual & Operacional \\
& Ambiente Organizacional \\
& Experiência/Crescimento \\
& Reconhecimento \\
\hline Vida Social & Amadurecimento \\
& Relacionamento Familiar \\
& Importância/Autoestima \\
& Rotina/Tempo \\
\hline Futuro & Conquistas/Sonhos \\
& Trabalho que gosta \\
& Dinheiro \\
& Carreira \\
\hline
\end{tabular}

Fonte: elaborado pelos autores (2017). 
A primeira categoria, significado do trabalho, diz respeito ao pensamento do jovem sobre o trabalho, que foi relacionada com os aspectos conhecimento/experiência, responsabilidade/amadurecimento, dinheiro/necessidade, realização, independência e futuro. A segunda categoria, trabalho atual, refere-se ao momento atual de trabalho que os jovens pesquisados estão vivenciando. Este conteúdo foi abordado por meio de pontos como: operacional, ambiente organizacional, experiência/crescimento e reconhecimento. A terceira categoria, vida social, expressa o que as pessoas perceberam após o ingresso no trabalho com relação à vida social e familiar. As repostas focaram o amadurecimento pessoal, relacionamento familiar, importância/autoestima e mudança de rotina/tempo. A quarta categoria, denominada futuro, aborda questões sobre perspectivas futuras e, a partir das declarações, tem-se as subcategorias: conquistas/sonhos, trabalhar naquilo que gosta, dinheiro e carreira.

\section{ANÁLISE E INTERPRETAÇÃO DOS RESULTADOS}

A análise de resultados inicia com a caracterização dos entrevistados (subcapítulo 4.1) e, após, aborda as categorias a posteriori descritas na metodologia (subcapítulos 4.2 a 4.5 ). Ainda, como parte complementar da análise, serão expostas as saídas do software Nvivo $11^{\circledR}$, constante no subcapítulo 4.6.

\subsection{CARACTERIZAÇÃO DOS ENTREVISTADOS}

Foram entrevistados 50 jovens com idades entre 15 e 19 anos, predominando as idades de 16 e 17 anos, sendo 29 do sexo feminino e 21 do sexo masculino. Segundo Sposito (2008), nessa fase da vida são construídos elementos de identidade pessoal e de grupo. É uma etapa de experimentação onde existem vários caminhos e entornos para o início da vida adulta, sendo um deles a inserção no mundo do trabalho.

O tempo de contrato de aprendiz desses jovens era variado, o que possibilitou diferentes percepções em função da experiência e de cada momento que cada um se encontrava. Na caracterização do perfil, um dos questionamentos tratava da renda familiar, foi possível constatar que 30 jovens tinham renda familiar inferior à três salários mínimos, enquanto que os demais tinham renda superior a esse valor.

\subsection{PERCEPÇÕES EM RELAÇÃO AO SIGNIFICADO DO TRABALHO}

Essa questão trouxe à tona aspectos que possibilitaram emergir as subcategorias conhecimento / experiência, responsabilidade / amadurecimento, dinheiro / necessidade, realização, independência e futuro. O Quadro 2 apresenta as respostas que contextualizam as subcategorias identificadas.

Quando os entrevistados expõem o significado para conhecimento ou experiência, eles remetem ao crescimento profissional e na preocupação em adquirir conhecimento para evoluir pessoalmente e profissionalmente. No entanto, quando os entrevistados citaram sobre responsabilidades/amadurecimento, esse aspecto se referiu ao momento em que eles estão passando em função da idade e pensamento, pois acreditam que o trabalho possa fazer com que eles adquiram mais responsabilidades, guiando melhor seus passos.

No significado de dinheiro, a maioria dos entrevistados relacionam o trabalho ao dinheiro e mais outro aspecto como realização, crescimento, independência. O dinheiro também apareceu sozinho em alguns entrevistados, como único significado do trabalho. 
Quadro 2 - Subcategorias do significado do trabalho $\mathrm{x}$ respostas dos entrevistados

\begin{tabular}{|c|c|}
\hline Conhecimento/experiência & $\begin{array}{l}\text { "Que é de grande importância pois adquirimos conhecimento, } \\
\text { experiência entre outros". } \\
\text { "Para mim é gratificante, pois o trabalho me proporcionou novas } \\
\text { experiências e conquistas". }\end{array}$ \\
\hline Responsabilidade/amadurecimento & $\begin{array}{l}\text { "Responsabilidade, que eu e estou crescendo e tenho que me ligar } \\
\text { nisso". } \\
\text { "Penso em ter mais responsabilidades, mais eficiência sem contar com } \\
\text { o dinheiro". }\end{array}$ \\
\hline Dinheiro/necessidade & $\begin{array}{l}\text { "Pra mim é trocar a mão de obra por dinheiro". } \\
\text { "Realmente, a primeira coisa em que penso é a remuneração". }\end{array}$ \\
\hline Realização & $\begin{array}{l}\text { "Realizações, pois quando se trabalha você pode realizar o quem tem } \\
\text { vontade de fazer". } \\
\text { "Penso que estou fazendo meu papel na sociedade". }\end{array}$ \\
\hline Independência & $\begin{array}{l}\text { "Ser mais independente em relação ao dinheiro". } \\
\text { "Em ter seu próprio dinheiro, ter responsabilidades, não depender } \\
\text { somente dos pais". }\end{array}$ \\
\hline Futuro & $\begin{array}{l}\text { "Trabalho para mim é uma forma de construir um futuro, com } \\
\text { experiências diferentes, com um ganho podendo comprar ou investir } \\
\text { em coisas para o futuro". } \\
\text { "Quando falam a palavra trabalho eu penso que o meu futuro tá ali, } \\
\text { porque eu sempre queria começar a trabalhar desde cedo para ter meu } \\
\text { dinheiro para eu não ficar dependendo da mãe e do pai". }\end{array}$ \\
\hline
\end{tabular}

Fonte: elaborado pelos autores (2017).

A realização pessoal mencionada pelos entrevistados se refere ao seu espaço dentro da sociedade ou ao sentimento que ele lhe proporciona, como prazer, orgulho, importância. A independência foi citada pelos entrevistados na perspectiva financeira e familiar, possibilitando não depender mais dos pais. Alguns citaram em poder sair de casa, se sustentar de forma independente. Os entrevistados que relacionaram o significado do trabalho com o futuro, demonstraram seus sonhos, desejos e suas perspectivas, identificando que o trabalho é algo para a vida e que precisam dele para suas conquistas pessoais.

A partir dessa primeira questão, pode-se identificar uma aproximação parcial com os autores Alberton e Piccinini (2009), pois o sentido do trabalho deve estar relacionado ao prazer em trabalhar, ao uso da criatividade, ao aprendizado e ao reconhecimento das competências do trabalhador. No entanto, apenas as características de aprendizado (conhecimento/experiência) e o prazer (realização) foram evidenciadas nas entrevistas. Os fatores de criatividade (autonomia, liberdade de trabalho, flexibilidade) e reconhecimento não foram abordados pelos entrevistados.

\subsection{TRABALHO ATUAL}

A maioria dos jovens falou muito bem sobre seus locais de trabalho, ressaltando muitos aspectos positivos. As subcategorias que ficaram evidenciadas com as respostas dos jovens foram: operacional; ambiente organizacional; experiência/crescimento; reconhecimento.

A subcategoria operacional se refere às práticas da rotina de trabalho, relacionando aos procedimentos, atividades, e, eventualmente, relacionando com a sua satisfação em relação à empresa ou à sua função. A experiência/crescimento diz respeito à oportunidade vivenciada pelo jovem na empresa, gerando novos conhecimentos e proporcionando um crescimento profissional reconhecido por esse indivíduo. Já o reconhecimento, está atrelado 
à importância desse aprendiz no trabalho, reconhecido ou não pela empresa, mas evidenciada na situação atual. No Quadro 3, seguem algumas respostas selecionadas para reforçar as análises.

Quadro 3 - Subcategorias do trabalho atual $\mathrm{x}$ respostas dos entrevistados

\begin{tabular}{|l|l|}
\hline \multirow{2}{*}{ Operacional } & $\begin{array}{l}\text { "Faço coisas interessantes que não sabia que existia". } \\
\text { "Meu trabalho é legal, não é pesado, é o trabalho perfeito para um } \\
\text { aprendiz". }\end{array}$ \\
\hline \multirow{5}{*}{ Experiência/Crescimento Organizacional } & $\begin{array}{l}\text { "A situação do trabalho está tranquila, o meu trabalho está sendo bem } \\
\text { legal, meu convívio com meus colegas está sendo bom". } \\
\text { "Onde eu trabalho é um local muito agradável, com pessoas legais". }\end{array}$ \\
\hline "Estou muito satisfeita com o meu trabalho e com o meu desenvolvimento \\
profissional além que amadureci muito". \\
"Gosto muito de meu trabalho atual, realizo várias atividades que \\
contribuem para minha experiência". \\
"Estou sendo importante para minha empresa, me dedico bastante". \\
"Certos momentos achei que minha função dentro da empresa não era de \\
grande valia, me sentindo um pouco inútil, mas conversei com meu chefe \\
e ele me mostrou a importância da minha atividade, favorecendo o meu \\
rendimento ao trabalhar".
\end{tabular}

Fonte: elaborado pelos autores (2017).

Na segunda questão, ao contrário da primeira, somente um entrevistado comentou sobre a remuneração, enquanto os demais citaram os pontos de sentido, sentimento e operação do trabalho. Em contrapartida, o reconhecimento, citado pelos autores Alberton e Piccinini (2009), não mencionado inicialmente, aparece nesse momento, corroborando com a teoria e sua importância para o indivíduo. No entanto, o que mais marcou nas entrevistas foi o ambiente organizacional, as relações com colegas e com a empresa, convergindo com o prazer de trabalhar. Esse ponto também foi resultado da pesquisa dos autores.

\subsection{INFLUÊNCIA DO TRABALHO NA VIDA SOCIAL E FAMILIAR}

Para essa pergunta, surgiram as subcategorias amadurecimento, relacionamento familiar, importância/autoestima, rotina/tempo. O amadurecimento, descrito nas entrevistas, remete à responsabilidade tanto pessoal, quanto profissional, financeiro e/ou familiar. As repostas com esse quesito mostraram que os jovens, a partir do trabalho, aumentam sua percepção para a responsabilidade e também para o seu gerenciamento financeiro (para si ou para sua família). Quanto ao relacionamento familiar, os jovens perceberam uma melhora no relacionamento com seus pais, que agora tem orgulho do filho que trabalha, que ganhou responsabilidades e ajuda no sustento da casa.

A importância/autoestima é ligada diretamente ao indivíduo, como ele se percebe na vida social com o trabalho. Nesse ponto, foram relacionados aspectos ligados à amigos, vida social mais ativa. Os entrevistados ressaltaram que ganharam mais liberdade e independência quando desejam sair, pois agora tem renda para sustentar seus lazeres, além de ter a oportunidade de conhecer pessoas novas e fazer novos laços de amizade.

A autoestima em relação à família também foi comentada, pois os jovens adquiriram uma posição de destaque na família, tornando-se um provedor de renda. Com relação à rotina/tempo, a limitação de tempo para saírem com amigos, realizarem atividades esportivas e de lazer, foram relatadas pelos jovens. O Quadro 4 apresenta as respostas referentes a essa questão. 
Quadro 4 - Subcategorias da vida social $\mathrm{x}$ respostas dos entrevistados

\begin{tabular}{|c|c|}
\hline Amadurecimento & $\begin{array}{l}\text { "Sim, melhorou bastante pelo fato que perdemos a inocência de criança e } \\
\text { aprendemos a conversar adequadamente com adultos e isso aconteceu } \\
\text { comigo e ajudou bastante". } \\
\text { "Em parte, como na forma de me comunicar e relacionar com pessoas } \\
\text { novas". }\end{array}$ \\
\hline Relacionamento Familiar & $\begin{array}{l}\text { "Sim, depois que comecei a trabalhar o meu diálogo com os meus pais } \\
\text { melhorou muito, Sim, meus familiares me veem com outros olhos sabe, } \\
\text { minha mãe tem mais orgulho de mim". } \\
\text { "Parece que virei adulto, conversamos mais coisas adultas. Diminuiu as } \\
\text { brigas, fico mais tempo com eles (família)". }\end{array}$ \\
\hline Importância/Autoestima & $\begin{array}{l}\text { "Na sociedade eu me sinto mais homem, mais responsável e mais } \\
\text { independente". } \\
\text { "Sim, a partir da renda que ele me traz consigo sair mais com meus amigos, } \\
\text { visitar lugares novos". }\end{array}$ \\
\hline Rotina/Tempo & $\begin{array}{l}\text { "Sim, pois sobra pouco tempo para a família por ter as tarefas da escola". } \\
\text { "Influencia um pouco pois só chego em casa de noite e só posso conversar } \\
\text { com a minha família durante a noite". }\end{array}$ \\
\hline
\end{tabular}

Fonte: elaborado pelos autores (2017).

Relacionando os dados com a literatura, Ruiz-Quintanilla e Claes (2000) mencionam uma das dimensões do trabalho, a centralidade do trabalho, é relacionada à identificação pessoal com o trabalho, ao seu valor e importância em relação às outras esferas da vida. Nessa dimensão, é possível perceber a influência familiar, social e importância/autoestima que o trabalho proporciona ao trabalhador, extraída das entrevistas. A autoestima citada pelos entrevistados é reconhecida pelos autores Osipow e Fitzgerald (1986), pois afirma que ter um trabalho valorizado pela sociedade - e ter sucesso nele - aumenta a autoestima e facilita o desenvolvimento de um senso de identidade cada vez mais seguro e estável.

\subsection{FUTURO NO TRABALHO}

Foi percebida uma atitude muito positiva nas respostas à essa questão. Um otimismo significativo tomou conta das colocações dos jovens aprendizes sobre seu futuro no plano de trabalho. Perspectivas construídas a partir da oportunidade do primeiro emprego.

Percebe-se que o sonho com um futuro melhor, com uma vida melhor, com conquistas pessoais e profissionais está contido em quase todas as respostas, gerando a subcategoria conquistas/sonhos. Eles reforçaram que é por meio do trabalho que vão realizar seus sonhos.

A outra subcategoria que emergiu das entrevistas foi a de trabalhar naquilo que gosta como principal desejo para o futuro. Dinheiro foi outro aspecto citado, porém numa minoria.

A subcategoria mais citada foi a carreira, a qual o jovem pretende ter, continuar e crescer com ela. Citaram que vão ter um futuro bom, com grandes oportunidades, com muita experiência, crescendo na profissão, obtendo muito sucesso, sendo dono da própria empresa. Uma pequena parcela de respondentes demonstrou uma baixa expectativa em relação ao futuro profissional, demonstrando uma incerteza que pode estar ligada à sua atual condição de trabalho. No Quadro 5, podem ser observadas algumas respostas que marcam essa questão. 
Quadro 5 - Subcategorias do futuro $\mathrm{x}$ respostas dos entrevistados

\begin{tabular}{|c|c|}
\hline Conquistas/Sonhos & $\begin{array}{l}\text { "Me vejo realizando meu sonho e atuando na área que eu quero". } \\
\text { "Vejo um futuro melhor, um futuro onde terei as minhas coisas sem depender de } \\
\text { ninguém". }\end{array}$ \\
\hline $\begin{array}{l}\text { Trabalho que } \\
\text { gosta }\end{array}$ & $\begin{array}{l}\text { "Uma pessoa de sucesso, bem e trabalhando na área que eu gosto". } \\
\text { "Fazendo o que eu gosto de fazer, exercendo um cargo em um hospital, ajudando } \\
\text { pessoas". }\end{array}$ \\
\hline Dinheiro & $\begin{array}{l}\text { "Com um emprego fixo, renda boa e em uma área que eu goste". } \\
\text { "Me vejo trabalhando no que eu gosto e tendo uma boa renda para manter bem a } \\
\text { minha família". }\end{array}$ \\
\hline Carreira & $\begin{array}{l}\text { "Eu me vejo como uma grande empresária e tendo meu próprio escritório". } \\
\text { "Pretendo estudar e crescer dentro de alguma empresa ou criar a minha". }\end{array}$ \\
\hline
\end{tabular}

Fonte: elaborado pelos autores (2017).

A partir das perspectivas do futuro, as entrevistas se direcionaram para o trabalho que gosta e para a carreira. Assim, as expectativas dos jovens vão ao encontro da autora Morin (2001), que descreve o sentido do trabalho em três componentes: a significação do trabalho (representações que o sujeito tem de sua atividade e o valor que lhe atribui), a orientação do sujeito ao trabalho (inclinação para o trabalho, o que busca e o que guia suas ações) e a coerência que o trabalho tem para o sujeito, ou seja, o equilíbrio que ele espera de sua relação com o trabalho. Portanto, fazer o que gosta e buscar por uma carreira ou crescimento profissional são componentes do significado do trabalho.

\subsection{ANÁLISE COM AUXÍLIO DO SOFTWARE}

$\mathrm{Na}$ última parte da análise, foi utilizado o software Nvivo $11^{\circledR}$ para agregar nas interpretações das entrevistas. O primeiro resultado fornecido pelo software foi a nuvem de palavras, que é uma ilustração gráfica das palavras mais citadas no conteúdo analisado. A nuvem de palavras pode ser visualizada na Figura 1.

Figura 1 - Nuvem de palavras

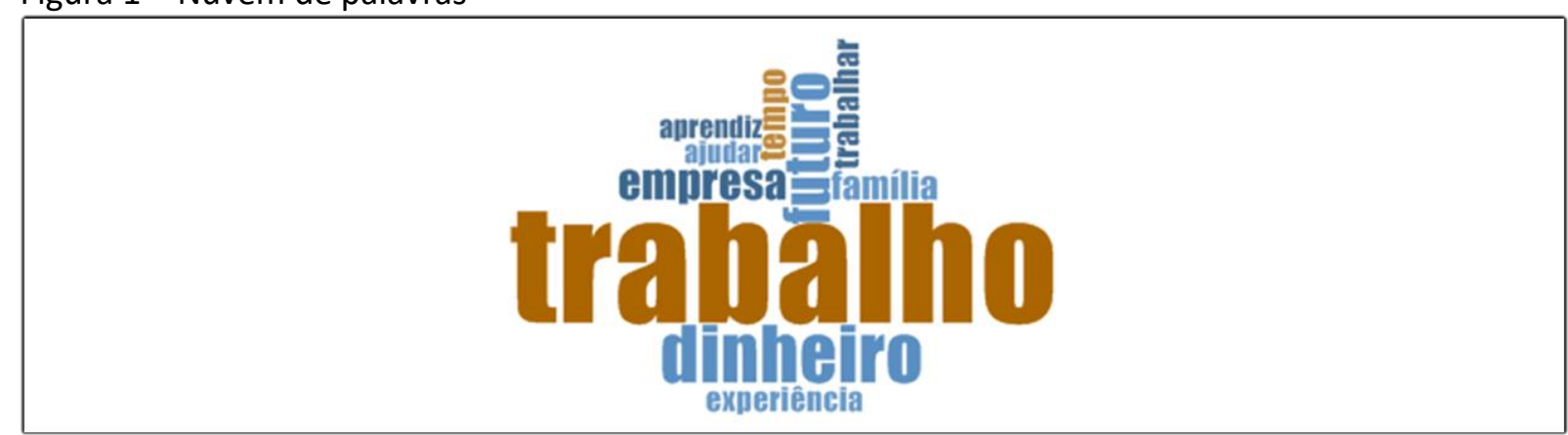

Fonte: extraído do software Nvivo $1^{\circledR}$ (2017).

A nuvem de palavras evidencia os termos mais citadas nas entrevistas, o qual a palavra "trabalho" destacou-se perante às demais, por se tratar do ambiente em que a pesquisa foi desenvolvida. As outras palavras, por estarem ligadas diretamente ou indiretamente ao trabalho, localizaram-se ao redor. O segundo resultado fornecido pelo software a ser utilizado foi a de frequência de palavras, onde o software fornece uma contagem de palavras mais significantes que foram citadas pelos entrevistados e que podem ser utilizadas no estudo, verificando se existe compatibilidade com os objetivos da pesquisa. A frequência de palavras está ilustrada no Quadro 6. 
Quadro 6 - Frequência de palavras

\begin{tabular}{|l|c|}
\hline PALAVRAS & CONTAGEM \\
\hline TRABALHO & 95 \\
DINHEIRO & 44 \\
FUTURO & 35 \\
EMPRESA & 26 \\
FAMÍLIA & 20 \\
TEMPO & 19 \\
TRABALHAR & 18 \\
EXPERIÊNCIA & 17 \\
AJUDAR & 15 \\
APRENDIZ & 15 \\
\hline
\end{tabular}

Fonte: extraído do software Nvivo $11^{\circledR}$ (2017).

Os quatro termos mais citados no decorrer das entrevistas e selecionados pelo software, de acordo com sua relevância para o estudo, foram as palavras trabalho (citada 95 vezes), dinheiro (citada 44 vezes), futuro (citada 35 vezes) e empresa (citada 26 vezes). A partir da frequência de palavras, fica evidente a relação entre trabalho, dinheiro, futuro e empresa, pois o indivíduo busca, por meio do trabalho, além de melhores condições de vida, trabalho e lazer, trabalho e família, tempo e espaço, mercado de trabalho e empregabilidade (GAMST, 1995).

Por fim, o software forneceu o cluster de palavras, que pode ser visualizado na Figura 2. O cluster de palavras tem como objetivo relacionar os trechos separados por categorias e promover ligações entre eles facilitando a análise.

Figura 2 - Cluster de palavras

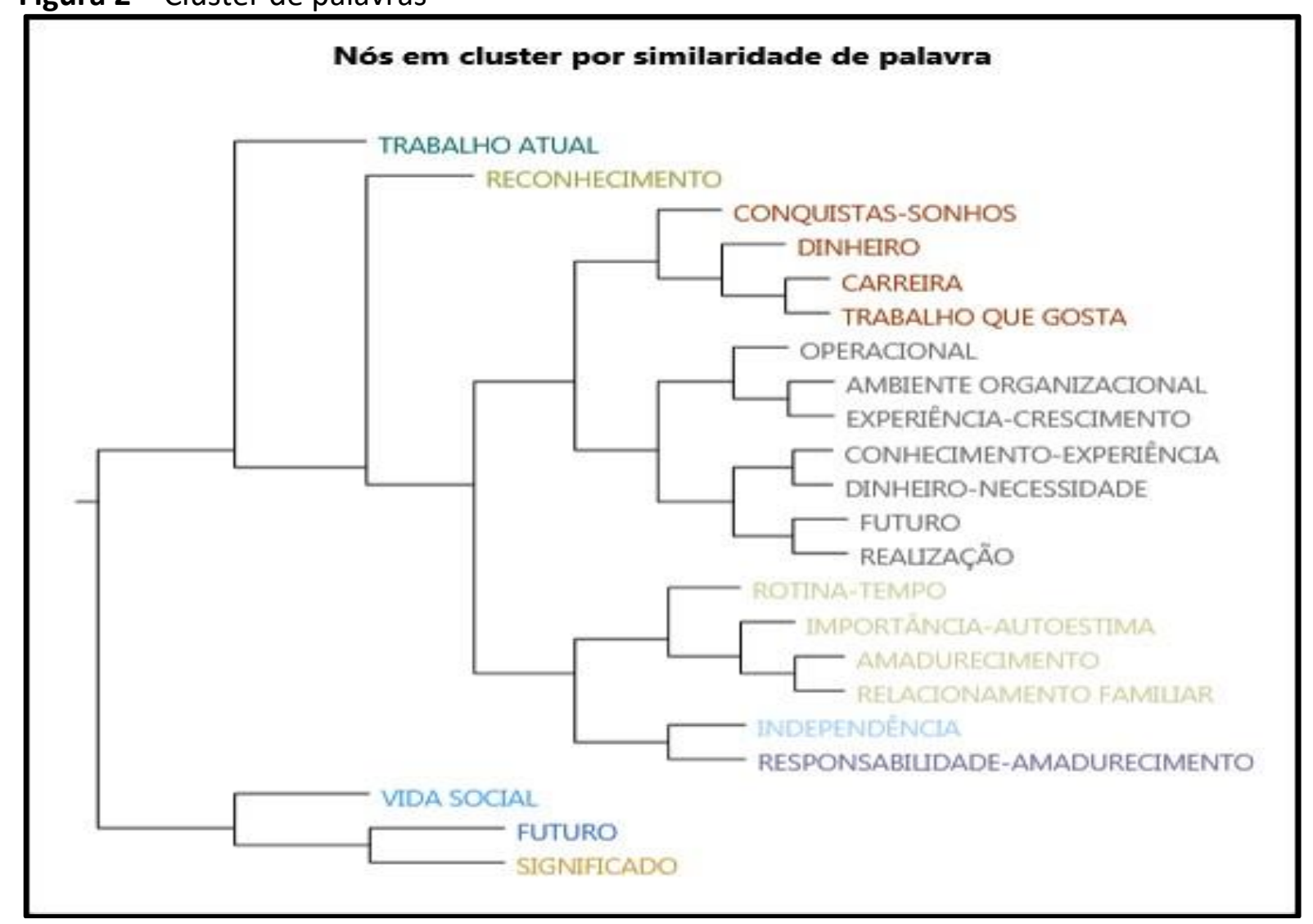

Fonte: extraído do software Nvivo $11^{\circledR}(2017)$.

RGO - Revista Gestão Organizacional, Chapecó, v. 12, n. 1, p. 17-38, jan./abr., 2019. 
A primeira relação encontrada no cluster liga a palavra trabalho atual e reconhecimento, evidenciando que o trabalho atual busca o reconhecimento da empresa, pois o trabalho pode ser definido como uma forma de entendimento subjetivo do indivíduo acerca das promessas de trocas recíprocas entre ele e a organização (ROUSSEAU, 1995). A partir dessa troca, os resultados valorizados do trabalho são elementos cognitivos que agem como guias, como ideais, sobre a postura do indivíduo no trabalho - o que ele gostaria de realizar por meio do trabalho e o que ele espera deste (MOW, 1987).

A palavra conquistas/sonhos vêm acompanhada das palavras dinheiro, carreira e trabalho que gosta. Essa ligação sugere que as conquistas são realizadas por meio de dinheiro, carreira e trabalhar naquilo que gosta. A palavra operacional está ligada com ambiente organizacional e experiência/crescimento, mostrando que, a partir da realização do trabalho operacional, alcança-se um ambiente organizacional e experiência/crescimento que se espera.

Outra ligação identificada são as palavras conhecimento/experiência e dinheiro/necessidade com futuro e realização. Fica evidente a ligação entre as palavras, uma vez que o conhecimento/experiência e dinheiro/necessidade trazem no futuro realização, corroborando com o autor Marx (1971). O autor menciona que a importância do trabalho na vida do indivíduo não é medida apenas naquilo que ele produz, mas também na sua autorrealização, que só pode ser compreendida por meio da sua ligação com a concepção do trabalho.

A palavra rotina/tempo é relacionada com importância/autoestima, amadurecimento e relacionamento familiar. É possível entender que o a rotina/tempo alterada em função do trabalho, influencia na importância/autoestima do indivíduo e traz amadurecimento e relacionamento familiar. A rotina/tempo também está ligada com as palavras independência e responsabilidade/amadurecimento, indicando que a rotina/tempo alterada em função do trabalho trazem independência e responsabilidade/amadurecimento. A relação de conflito pessoal é indicada pelos autores Ardichvili e Kuchinke (2009), pois o trabalho, ao se apresentar como fonte de experiências humanas, proporciona alegria, exuberância e satisfação, mas também desapontamento, tristeza, angústia e desespero.

Por fim, a palavra vida social está ligada nas palavras futuro e significado, evidenciando que a vida social cria significado para o futuro. Essa relação é indicada pelos autores Spink (2010) e Lima (2013), que descrevem que a produção de sentidos se dá num contexto em interação e com interferências por questões de ordem histórica e cultural, permitindo com que a pessoa se relacione com situações e fenômenos sociais. Assim, as pessoas constroem o mundo ao construir sentidos, através de repertórios individuais e sua identidade para esses sentidos.

A partir da entrevista, foi possível perceber a relevância que o Programa Aprendiz Legal oferecido pelo CIEE tem na vida dos jovens pesquisados. Quase a totalidade se referiu ao programa como fator determinante na construção de suas vidas profissionais. Eles destacaram, em suas respostas, as oportunidades oferecidas a partir do programa de aprendizado. Citaram a conquista do primeiro emprego, a aquisição de experiência, a inserção no mercado de trabalho, a nova visão da vida profissional, a melhora na qualidade de vida (do ponto de vista financeiro), o crescimento pessoal, o "ganho" de responsabilidade, entre outras. Eles perceberam que o Programa Aprendiz facilitou a entrada no mercado de trabalho e que essa inserção, sem o programa, poderia ter sido mais difícil.

Outro ponto identificado nas entrevistas é que todos os jovens sinalizaram que 
pretendem dar continuidade aos estudos. Boa parte já definiu qual será seu curso de formação superior, uma parcela menor ainda está em dúvida entre um ou outro curso e poucos ainda não sabem o que vão cursar. Foi interessante constatar a unanimidade sobre esse aspecto, mas de certa forma, não foi uma surpresa, já que o Programa Aprendiz Legal, dentro de suas diretrizes, reforça continuamente aos jovens a importância da continuidade dos estudos para o futuro. Nesse sentido, pode-se afirmar que os estudos apresentam um valor para o jovem que, possivelmente, foi originado através do Programa de Aprendizagem, que possui os estudos como um dos pilares do trabalho.

\section{CONSIDERAÇÕES FINAIS}

Esse estudo teve como objetivo compreender o que os jovens aprendizes do CIEE percebem acerca do significado do trabalho no início de suas vidas profissionais. A possibilidade de adquirir experiência, continuar os estudos, ajudar a família, aprimorar seus conhecimentos e estarem inseridos no mundo do trabalho, faz com que eles se sintam valorizados como seres humanos diante das suas famílias e da sociedade. Jacques (1996) aponta que o papel do trabalhador é um dos papéis sociais mais representativos do eu: os atributos do trabalho, a associação do espaço e/ou da categoria de trabalho ao prestígio ou desprestígio social, tudo reverbera na qualificação de si mesmo.

A compreensão do significado do trabalho para os jovens aprendizes do CIEE, unidade operacional de Caxias do Sul, foi observada no estudo de Morin (2001), onde estão ressaltadas as cinco principais razões que levam as pessoas a trabalharem: realizar-se e atualizar suas competências e potencialidades; adquirir segurança e ser autônomo; relacionar-se com os outros e estar vinculado a grupos; prestar serviço à sociedade; e dar sentido à vida, incluindo fazer e manter-se ocupado.

A oportunidade de se relacionar com outras pessoas, relatada pelos jovens na pesquisa, os ajuda, a partir das trocas estabelecidas, a formar uma identidade profissional. 0 processo de trabalho ajuda o indivíduo a descobrir e formar sua identidade. Dessa forma, o trabalho é uma atividade que coloca as pessoas em relação umas com as outras, o que também contribui para o desenvolvimento de suas identidades. $O$ fato de estar em contato com outras pessoas age como um verdadeiro estimulante para si mesmo, não apenas para o desenvolvimento de sua identidade pessoal, mas também contribuindo para o desenvolvimento dos laços sociais (MORIN, 2001).

Devido ao programa ser socioassistencial, ficou evidenciada a importância da renda para os jovens aprendizes. Diante desse contexto, é inegável que o dinheiro consolida a autonomia desses jovens com indivíduos na sociedade, pois além de poderem ajudar me casa, o dinheiro possibilita que eles tenham uma vida social mais ativa, além de possibilitar que tenham independência perante seus pais.

Foi percebido que apenas as características de aprendizado (conhecimento/experiência), dinheiro e o prazer (realização) foram evidenciadas nas entrevistas quanto ao significado de trabalho. Os fatores de criatividade (autonomia, liberdade de trabalho, flexibilidade) e reconhecimento não foram abordados pelos entrevistados, parecendo que o significado do trabalho tem apenas um fim e não um meio de como executá-lo. Esses aspectos percebidos pelos jovens remetem à faixa etária a qual estão inseridos, indicando que, mais importante do que às condições de trabalho, é o que ele proporciona durante sua jornada.

Outro ponto identificado nas entrevistas é que o trabalho melhora a relação do jovem 
com a família. Isso ocorre porque eles conseguem ajudar em casa financeiramente, além de amadurecerem através das responsabilidades que o trabalho lhe atribui. $O$ trabalho propicia que o jovem melhore sua autoestima, melhorando seu relacionamento social (amigos e família).

Por fim, pode-se perceber, a partir dos resultados com o software, que os jovens buscam reconhecimento no trabalho atual, seja ele pela empresa ou pela família. A importância do reconhecimento como um membro da empresa e/ou como um indivíduo provedor de recursos para a família, poderá promover o amadurecimento desse jovem, além de propulsar seu desempenho e seu desenvolvimento profissional no início de sua carreira.

Ainda, que o jovem entrevistado pensa que as conquistas são realizadas por meio de dinheiro, carreira e trabalhar naquilo que gosta. No entanto, essa perspectiva é o que ele almeja para o futuro como ideal, mas nem sempre poderá ser atendida ao longo da sua vida profissional. Dessa forma, deve-se pensar como conduzir os jovens no início de sua carreira, para que ele não se desmotive ou se frustre com a sua dificuldade em ascensão de forma acelerada. Por isso, as empresas deverão aprender a conduzir os jovens para que eles entendam aonde poderão crescer, aonde deverão se desenvolver, alinhando, paralelamente, com suas expectativas e objetivos de trabalho.

O estudo possui limitações por ser um estudo de caso único, não permitindo a generalização dos resultados. Portanto, para pesquisas futuras, sugere-se replicar esse estudo aos estagiários do CIEE ou nas escolas para jovens do ensino médio.

\section{AGRADECIMENTOS}

O presente trabalho foi realizado com apoio da Coordenação de Aperfeiçoamento de Pessoal de Nível Superior - Brasil (CAPES) - Código de Financiamento 001", conforme PORTARIA № 206, de 4 de setembro de 2018". Agências: CAPES, FAPERGS, CNPQ, UCS.

\section{REFERÊNCIAS}

AGUIAR, W. M. J. Sentidos e significados do professor na perspectiva sócio-histórica: relatos de pesquisa. São Paulo: Casa do Psicólogo, 2006.

AGUIAR, W. M. J.; SANCHEZ, S. G.; FURTADO, O.; ROSA, E. Z.; KAHHALE, E. P.; MARCHESAN, E. C.; SVARTMAN, B.; LIEBESNY, B. Reflexões sobre sentido e significado. In: BOCK, A. M. B.; GONÇALVES, M. G. M. A dimensão subjetiva da realidade: uma leitura sócio-histórica. São Paulo: Cortez, 2009. p. 54-72.

AGUIAR, M.; HURST, E. Measuring Trends in Leisure: The Allocation of Time Over Five Decades. The Quarterly Journal of Economics, v. 122, n. 3, p.969-1006, 1 ago. 2007. Oxford University Press (OUP). http://dx.doi.org/10.1162/qjec.122.3.969.

\section{ALBERTON, D. M. Os sentidos atribuídos ao trabalho pelos profissionais do ramo}

publicitário de Porto Alegre. 2008. Dissertação (Mestrado de Administração) - Universidade Federal do Rio Grande do Sul, Porto Alegre, 2008.

ALBERTON, D. M.; PICCININI, V. C. O. Sentido do Trabalho em Agências de Publicidade. In: Encontro da Associação Nacional Pós-Graduação e Pesquisa em Administração, 33, São 
Paulo. Anais [...] São Paulo, Anpad, 2009.

ALONSO, F. S. A.; COSTA, D. V. F.; FERREIRA, V. C. P.; BORGES, M. S. Trabalho e Aprendizagem: as perspectivas de futuro profissional de jovens aprendizes na cidade de Três Rios, RJ. Revista de Administração da UNIFATEA, v. 13, n. 13, p. 64-84, maio 2018. ISSN 2176-8412.

AMAZARRAY, M. R.; THOMÉ, L. D.; SOUZA, A. P. L.; POLETTO, M.; KOLLER, S. H. Aprendiz versus trabalhador: adolescentes em processo de aprendizagem. Psicologia: Teoria e Pesquisa, v. 25, n. 3, p. 329-338, 2009. http://dx.doi.org/10.1590/S010237722009000300006.

ARDICHVILI, A.; KUCHINKE, K. P. International perspectives on the meanings of work and working: current research and theory. Advances in Developing Human Resources, v. 11, n. 2, p. 155-167, 2009.

ARNETT, J. J. Emerging Adulthood(s). Bridging Cultural and Developmental Approaches to Psychology, p.255-275, 23 set. 2010. Oxford University Press. http://dx.doi.org/10.1093/acprof:oso/9780195383430.003.0012.

AVANZI, R. Impactos da revista agitação na visibilidade do CIEE: imagens e imaginários sociais. 2008. Dissertação (Mestrado em Comunicação e Práticas de Consumo) - Escola Superior de Propaganda e Marketing, São Paulo, 2008.

BARDIN, L. Análise de conteúdo. 3. ed. Lisboa: Edições, 2004.

BAUMAN, Z. Trabajo, consumismo y nuevos pobres. Editorial Gedisa, 2000.

BENDASSOLLI, P. F.; GONDIM, S. M. G. Significados, sentidos e função psicológica do trabalho: Discutindo essa tríade conceitual e seus desafios metodológicos. Avances en Psicología Latinoamericana, v. 32, n. 1, p. 131-147, 2014.

BORGES, L. O. Os atributos e a medida do significado do trabalho. Psicologia: Teoria e Pesquisa, v. 13, n. 2, p. 211-220, 1997.

Significado do trabalho e socialização organizacional: um estudo empírico entre trabalhadores da construção habitacional e de redes de supermercados. 1998. Tese (Doutorado de Psicologia Social do Trabalho) - Universidade de Brasília, Brasília, 1998.

BORGES, L. O.; BARROS, S. C. Inventário de significado do trabalho para trabalhadores de baixa instrução. In: PEIXOTO, A. L. A.; PUENTE-PALACIOS, K. Ferramentas de diagnóstico para organizações e trabalho: um olhar a partir da psicologia. Porto Alegre: Artmed, 2015. p. 232-260.

BRASIL. Lei no 11.788, de 25 de Setembro de 2008. Dispõe sobre o estágio de estudantes; altera a redação do art. 428 da Consolidação das Leis do Trabalho - CLT, e dá outras 
providências. Brasília: Casa Civil. Disponível em:

http://www.planalto.gov.br/ccivil_03/_ato2007-2010/2008/lei/l11788.htm. Acesso em: 25 fev. 2017.

CIEE - CENTRO DE INTEGRAÇÃO EMPRESA ESCOLA. O que é o CIEE? Disponível em: http://www.ciee.org.br/portal/institucional/oquee.asp. Acesso em: 25 fev. 2017.

CODO, W. Um diagnóstico do trabalho (em busca do prazer). In: TAMAYO, A.; BORGESANDRADE, J. E.; CODO, W. Trabalho, organizações e cultura. São Paulo: Cooperativa de Autores Associados, 1997. p. 21-40.

COSTA, S.H.B. Trabalho prescrito e trabalho real. In: MENDES, A. M.; MERLO, A. R. C.; VIEIRA, F. O. Dicionário crítico de gestão e psicodinâmica do trabalho. Curitiba: Juruá Editora, 2013.

DEJOURS, C. Le choix: souffrir au travail n'est pas une fatalité. Paris: Bayard, 2015.

1, p. 13-16, 2011.

Psicopatologia do trabalho-psicodinâmica do trabalho. Laboreal Porto, v. 7, n.

DUTRA-THOMÉ, L.; KOLLER, S. H. O significado do trabalho na visão de jovens brasileiros: uma análise de palavras análogas e opostas ao termo" trabalho". Revista Psicologia Organizações e Trabalho, v. 14, n. 4, p. 367-380, 2014.

DUTRA THOMÉ, L.; QUEIROZ TELMO, A.; KOLLER, S. H. Inserção laboral juvenil: contexto e opinião sobre definições de trabalho. Paidéia, v. 20, n. 46, 2010.

GAMST, F. C. Meanings of work: Considerations for the twenty-first century. Suny Press, 1995. GOULART, P. M. Adaptação do questionário sobre significados do trabalho-QST para o Brasil. Estudos de Psicologia, v. 14, n. 2, p. 123-131, 2009.

HARPER, D. Online Etymology Dictionary. 2001. Disponível em: http://etymonline.com/?search=schala. Acesso em: 16 set. 2017.

IBGE. Ensino: matrículas, docentes e rede escolar. 2015. Disponível em: http://cod.ibge.gov.br/17SFC. Acesso em: 20 fev. 2017.

JACQUES, M. G. C. Identidade e trabalho: uma articulação indispensável. Trabalho, Organizações e Cultura, v. 11, p. 21-26, 1996.

KUBO, S. H.; GOUVÊA, M, A. Análise de fatores associados ao significado do trabalho. Revista de Administração, v. 47, n. 4, p. 540-554, 2012. http://dx.doi.org/10.5700/rausp1057.

LHUILIER, D. Trabalho. Psicologia \& Sociedade, v. 25, n. 3, p. 483-492, p. 42-68, 2013.

LIMA, M.; TAVARES, N.; BRITO, M.; CAPELLE, M. O sentido do trabalho para pessoas com deficiência. Revista de Administração Mackenzie, v. 14, n. 2, 2013. 
LIMA, F. C. Ideologia e significado do trabalho: o caso dos trabalhadores por conta própria. 2016. Tese (Doutorado em Psicologia) - Universidade Federal do Rio Grande do Norte, Natal, 2016.

MARX, K.; ENGELS, F.; LASKI, H. J. Communist Manifesto: Socialist Landmark. George Allen and Unwin, 1971.

MATSUZAKI, H. H. O desafio da lei do jovem aprendiz: um estudo da aplicação da lei 10.097/00 como política pública na inclusão de jovens no mercado de trabalho. 2011. Dissertação (Mestrado em Administração) - Universidade de São Paulo, São Paulo, 2011.

MEDEIROS, R. Evolução das tipologias e categorias de áreas protegidas no Brasil. Ambiente \& Sociedade, v. 9, n. 1, p. 41-64, 2006.

MINAYO, M. C. S. Pesquisa social: teoria, método e criatividade. Petrópolis, RJ: Vozes, 2007.

MORIN, E. M. Os sentidos do trabalho. Revista de Administração de Empresas, v. 41, n. 3, p. 08-19, 2001.

MOW, International Research Team. The meaning of working. New York: Academic Press, 1987.

MINISTÉRIO DO TRABALHO E EMPREGO. Manual da Aprendizagem. Brasília: 2014.

OLIVEIRA, S. D.; PICCININI, V. C.; FONTOURA, D. D. S.; SCHWEIG, C. Buscando o sentido do trabalho. In: Encontro da Associação Nacional Pós-Graduação e Pesquisa em Administração, 28, 2004, Curitiba/PR. Anais [...] Curitiba, Anpad, 2004.

ONO, M. Os sentidos do trabalho: estudo com profissionais de TI que atuam em projetos na grande São Paulo. 2010. Dissertação (Mestrado em Administração) - Universidade Nove de Julho, São Paulo, 2010.

OSIPOW, S. H.; FITZGERALD, L. F. Theories of career development. Englewood Cliffs, NJ: Prentice-Hall, 1983.

PAULINO, D. S. Os significados do trabalho para jovens nem-nem e suas estratégias de inserção no mercado de trabalho. 2016. Dissertação (Mestrado em Psicologia) - Universidade Federal do Rio Grande do Norte, Natal, 2016.

PEIRO, J. M.; PRIETO, F.; ROE, R. A.; PRIETO, J. M. La aproximacion psicologia al trabajo en un entorno laboral cambiante. Tratado de Psicologia del Trabajo, v. 1, 15-36, 1996.

PIMENTA, S. G.; LIMA, M. S. L. Estágio e docência. São Paulo: Cortez, 2004.

QUINTANILLA, S. A. R.; WILPERT, B. Are work meanings changing? The European Work and Organizational Psychologist, v. 1, n. 2-3, p. 91-109, 1991. 
https://doi.org/10.1080/09602009108408515

ROCHA, S. S. A percepção de gestores educacionais e empresariais sobre o ingresso de estudantes de graduação a distância em programas de estágios: um estudo exploratório a partir do CIEE. 2008. Dissertação (Mestrado em Educação, Arte e História) - Universidade Presbiteriana Mackenzie, São Paulo, 2008.

ROUSSEAU, D. M. Psychological contracts in organizations. London: SAGE, 1995.

RUIZ-QUINTANILHA, S.A.; CLAES, R. MOW Research Programs. In: Katz; J.A. (Ed.), Databases for the study of entrepreneurship. New York: JAI/Elsevier Science Inc., 335-391, 2000.

SCHWEITZER, L.; GONÇALVES, J.; TOLFO, S. D. R.; SILVA, N. Bases epistemológicas sobre sentido(s) e significado(s) do trabalho em estudos nacionais. Revista Psicologia, Organizações e Trabalho, v. 16, n. 1, p.103-116, 2016. https://doi.org/10.17652/rpot/2016.1.680

SECRETARIA NACIONAL DA JUVENTUDE. Página Inicial. Disponível em: http://juventude.gov.br. Acesso em: 23 fev. 2017.

SOUZA, P. N. P.; NISKIER, A. Educação, estágio e trabalho. São Paulo: Integrare Editora, 2006.

SPINK, M. J. P. Psicologia Social e Saúde: trabalhando com a complexidade. Quaderns de Psicología, v. 12, n. 1, p. 41-56, 2010.

SPOSITO, M. P. Juventude e Educação. Interações, 2008.

TOLFO, S. R. Significados e sentidos do trabalho. In: BENDASSOLLI, P. F.; BORGES-ANDRADE, J. E. Dicionário de psicologia do trabalho e das organizações. São Paulo: Casa do Psicólogo. 2015. p. 617-625.

TOLFO, S. R.; PICCININI, V. Sentidos e significados do trabalho: explorando conceitos, variáveis e estudos empíricos brasileiros. Psicologia \& Sociedade, v. 19, p.38-46, 2007. http://dx.doi.org/10.1590/s0102-71822007000400007.

TOLFO, S. D. R.; COUTINHO, M. C.; ALMEIDA, A. D.; BAASCH, D.; CUGNIER, J. S. Revisitando abordagens sobre sentidos e significados do trabalho. In: Fórum CRITEOS 2005, Porto Alegre. Anais [...] Porto Alegre: UFRGS/EA, 2005. 1 CD-ROM.

ZANINI, P.; FÜRSTENAU, C. R.; PACINI, L.; MERLO, A. R. C. As transformações no serviço público e a saúde dos trabalhadores da seguridade social de Porto Alegre. In: CRESPO, A. R. M. Saúde do trabalhador no Rio Grande do Sul: Realidade, pesquisa e intervenção. Porto Alegre: Editora da UFRGS, 2004. p. 361-378. 